\title{
ÍNDICES DE SÍTIOS PARA Hovenia dulcis Thunberg NA REGIÃO CENTRAL DO ESTADO DO RIO GRANDE DO SUL, BRASIL
}

\section{SITES INDEX FOR Hovenia dulcis Thunberg IN THE CENTRAL REGION OF THE STATE OF RIO GRANDE DO SUL, BRAZIL}

\author{
Gerson Luiz Selle ${ }^{1}$ Frederico Dimas Fleig ${ }^{2}$ Elisabete Vuaden ${ }^{3}$ \\ Luiz Antônio Jacques de Albernard ${ }^{4}$ Evaldo Muñoz Braz ${ }^{5}$
}

\section{RESUMO}

Este trabalho teve como objetivo construir curvas índice de sítios florestais, a partir da altura dominante e idade, de populações localizadas na região central do Estado do Rio Grande do Sul. Para tanto, foram utilizadas informações de três povoamentos (sítios) com idades de 25 anos, localizados na Fundação de Pesquisa Agropecuária (FEPAGRO). Para classificar os sítios florestais, coletaram-se informações de 18 árvores dominantes nos locais, observando a metodologia para análise de tronco. Na construção das curvas de índice de sítio, foi o selecionado o modelo de Backman, ficando constatada a necessidade da construção de dois conjuntos de curvas, com intervalo de $2 \mathrm{~m}$, da idade de 5 a 25 anos, com idade índice de 25 anos. Para o Sítio I-A, foram geradas 3 curvas índices, de 22 a $24 \mathrm{~m}$ e, para os Sítios I-B+II+III, 6 curvas índices de 8 a $18 \mathrm{~m}$.

Palavras-chave: sítios florestais; classificação de sítios.

\section{ABSTRACT}

The main objective of this work is to study the index forest sites build, for the dominant height, of populations located in the central area of the state of Rio Grande do Sul. To do that, information from 3 stands located at FEPAGRO was used. To construct the curves index sites forest, information from 18 dominant trees was collected in the 4 sites, observing the methodology for the analysis of the bole. For the curves index site forest, the Backman model was, and it was verified the necessity of construction of two groups of index curves of sites, with space of $2 \mathrm{~m}$, from 4 to 25 years, and index age of 25 . To the site IA, 3 index curves were generated, from 22 to $24 \mathrm{~m}$ and, to the sites I-B+II+III, 6 index curves from 8 to $18 \mathrm{~m}$ were made.

Keywords: forest site; site clasification.

\section{INTRODUÇÃO}

No cenário florestal presente, o meio científico tem importante papel a desempenhar, fazendo com que às espécies atualmente plantadas tenham seu rendimento maximizado, propiciando que seja realizadas pesquisadas com novas espécies para aumentar o restrito grupo sobre o qual se tem domínio, no que tange ao cultivo e a condução dos povoamentos.

Uma das espécies que apresentam condições e características desejáveis, podendo ser cultivada, principalmente na região Sul do Brasil, é a uva-do-japão. Possuidora de madeira com excelentes características para uso industrial, em móveis, pisos, paredes e armações e, no meio rural, na forma de moirões bem como energia devido ao seu bom poder calorífico. Além disso, outras partes da árvore também podem ser utilizadas, como folhagem e frutos na alimentação bovina e, a floração com fins apícola (SELLE

1. Engenheiro Florestal, Dr., Funcionário do Departamento de Ciências Florestais, Centro de Ciências Rurais, Universidade Federal de Santa Maria, Av. Roraima, 1000, CEP: 97105-900, Santa Maria (RS). hs@smail.ufsm.br

2. Engenheiro Florestal, Dr., Professor Adjunto do Departamento de Ciências Florestais, Centro de Ciências Rurais, Universidade Federal de Santa Maria, Av. Roraima, 1000, CEP: 97105-900, Santa Maria (RS). fdfleig@smail.ufsm.br

3. Engenheira Florestal, MSc., Doutoranda pelo Programa de Pós-Graduação em Engenharia Florestal, Centro de Ciências Rurais, Universidade Federal de Santa Maria, Av. Roraima, 1000, CEP: 97105-900, Santa Maria (RS). elisabetevuaden@yahoo.com.br

4. Engenheiro Florestal, Profissional Autônomo Graduado pela Universidade Federal de Santa Maria, Rua Cristalino Machado Soares, 260, Casa 5, Bairro Camobi, CEP: 97110-2110, Santa Maria (RS). albernardl@hotmail.com

5. Engenheiro Florestal, Doutorando pelo Programa de Pós-Graduação em Engenharia Florestal da Universidade Federal de Santa Maria, Pesquisador da EMBRAPA Florestas, Estrada da Ribeira, Km 111, Caixa Postal, 319, CEP: 834111-000, Colombo (PR). evaldo@cnpf.embrapa.br

Recebido para publicação em 28/05/2009 e aceito em 6/07/2009. 
et al., 1993).

A espécie ocorre naturalmente entre as coordenadas $25^{\circ}$ e $41^{\circ}$ norte e $100^{\circ}, 142^{\circ}$ leste, principalmente, na China, Japão e Coréias. É uma planta heliófila, caducifólia, alcançando alturas de 10 a 15 $\mathrm{m}$, podendo chegar até a $25 \mathrm{~m}$, com copa globosa e ampla. Seu diâmetro médio à altura do peito varia entre 20 e $40 \mathrm{~cm}$ podendo chegar a $50 \mathrm{~cm}$. Seu tronco geralmente é reto e cilíndrico, apresentando fuste com até 8 $\mathrm{m}$ de comprimento, ramificação dicotômica, com ramos pubescentes enquanto jovem. Apresenta gemas dormentes subcorticais, rebrotando intensamente da touça, podendo ser manejada por talhadia, com rotações previstas de 10 a 15 anos (RIGATTO et al., 2001).

Segundo o mesmo autor, a espécie vem sendo cultivada na Argentina, Paraguai e no sul do Brasil, principalmente nas regiões de climas $\mathrm{Cfa}, \mathrm{Cfb}$ e $\mathrm{Cwa}$, de forma isolada ou em pequenos povoamentos. Em nosso país, a bacia do Rio Uruguai, nos estados de Santa Catarina e Rio Grande do Sul, no sudoeste do Paraná, são comuns pequenos plantios de uva-do-japão, em propriedades agrícolas, implantados por mudas ou, eventualmente, por semeadura direta no terreno.

Sempre que se pensa em conduzir uma floresta, visando planejar e maximizar a produção madereira, faz-se necessário saber o potencial produtivo do local no qual será implantado o povoamento. Assim é possível identificar as diferentes classes de produtividade que são denominadas de sítios.

Para isso, primeiramente devemos saber como é o "mundo" de uma planta. Num povoamento, uma árvore é influenciada pelos fatores genéticos integrados com os fatores climáticos, bem como a fertilidade do solo, o relevo e a competição com outros vegetais e animais.

A interação de todos estes fatores sobre a planta expressa a qualidade do sítio. Onde as condições de crescimento são boas o sítio é considerado bom e vice-versa (HUSCH et al., 1982).

Entretanto, determinado sítio pode ser excelente para uma espécie e ser ruim para outra, indicando que a qualidade do sítio deve ser definida individualmente para cada espécie. Dentro desse contexto, são vários os métodos que podem ser utilizados para a construção de índices de sítio.

De acordo com a variação do ambiente e das interações com o homem, as árvores apresentam taxas de crescimento diferenciadas ao longo do tempo. No entanto, é possível construir os fundamentos matemáticos para estimar o crescimento delas nos diferentes locais. Para a definição desses modelos matemáticos são empregadas técnicas de regressão linear, múltipla ou não linear.

Porém, quando se expressa o crescimento, por meio de funções matemáticas, é de vital importância analisar como é a forma de crescimento de árvores de locais diferentes, ou seja, se elas crescem segundo o mesmo padrão ou não. A ocorrência de diferenciação no crescimento da altura em diferentes sítios, para uma mesma espécie, é denominada polimorfismo entre as formas de crescimento, mostrando a necessidade de ajustar funções individuais para estes locais, obtendo com isso, maior precisão na descrição dos sítios.

Há muitas conceituações sobre sítio florestal na literatura, mas muitas conduzem ao mesmo princípio. Uma das primeiras definições foi feita por Spurr (1952), correspondendo à soma das condições efetivas sobre as quais uma planta ou comunidade se desenvolve. Sammi (1965), por sua vez, conceituou sítio de forma bem prática. Para ele, sítio é a classificação de uma determinada área referindo-se a sua capacidade de produzir madeira. Já Grey (1980) definiu o termo como um complexo integrado de todos os fatores ambientais dentro de uma área prescrita.

James (1969), afirma que ao classificarem-se sítios, entende-se estar voltado para dois propósitos principais, o de identificar o potencial de produtividade, objetivo esse mais importante, e também o de fornecer uma estimativa de referência para diagnosticar e prescrever o manejo do solo.

Historicamente, as primeiras aplicações dessas conceituações foram aplicadas no século XIX na Alemanha. O primeiro estudo sobre o assunto foi feito pelo botânico, engenheiro florestal e político finlandês Cajander, que, no início do século passado, criou a teoria das tipologias florestais. Considerando essa teoria, um sítio era classificado a partir da percentagem existente de cada espécie na vegetação ao nível do solo (PARVIAINEN e NAUMANN, 1986).

Para Selle (1993), na classificação de sítios dois métodos distintos são citados: o ambiental, que envolve os fatores físicos, topográficos e climáticos da região, e o das medições, cuja classificação é feita avaliando a capacidade de produção de cada unidade expressa pela altura dominante. Porém também é 
possível integrar os dois métodos, de modo a correlacionar a altura dominante com fatores do local como o solo, a altitude, a topografia, etc.

Por outro lado, Dacosta (2008) salienta que os métodos de classificação de sítios podem também ser divididos em diretos e indiretos. Os primeiros requerem a existência atual ou no passado de espécies de interesse no local onde a qualidade será avaliada. Segundo a pesquisadora, esses métodos dividem-se em: a) estimação pelo histórico da produção; b) estimação baseada em dados de volume do povoamento, e c) estimação baseada em dados de altura do povoamento. Já os métodos indiretos são divididos em: a) estimação pelas relações interespécies; b) estimação pelas características da vegetação inferior, e c) estimação pelos fatores topográficos, climáticos e edáficos.

No entanto, o método mais usado, segundo uma série de autores, é aquele que emprega a altura das árvores alcançada pelo povoamento nas diferentes idades de seu desenvolvimento. Por convenção, a altura dominante alcançada em uma determinada idade, recomendada próximo à idade de rotação, tida como "idade chave, idade índice ou de referência", é denominada de índice de sítio (SELLE, 1993).

A identificação da curva da altura sobre a idade, referenciada à altura na idade índice, define os índices de sítio absolutos. Da mesma forma, a relação altura/idade poderia ser identificada por números romanos (I, II, III, respectivamente, indicando do melhor ao pior sítio), dando origem às classes de sítio (BURGER, 1976). Também, de acordo com o método amostral que for usado para a obtenção dos dados, é definido que tipo de curva se obtém: as curvas harmônicas, anamórficas ou monomórficas e as naturais ou polimórficas (BATISTA e DO COUTO, 1986).

$\mathrm{Na}$ elaboração das curvas monomórficas, ajusta-se uma única função para todo conjunto de dados, obtendo-se uma curva guia. Depois disso, é adicionada uma série de curvas paralelas, com intercepto variável, acima e abaixo desta, as quais têm a mesma forma, diferindo somente em amplitude, por uma porcentagem fixa (ALDER, 1980; CLUTTER et al., 1983; SELLE et al., 2008). Já segundo Clutter et al. (1993), para o processo de construção de curvas polimórficas, são exigidas medições repetidas, em intervalos de tempo sucessivos (parcelas permanentes), ou através da técnica da análise de tronco de espécies que apresentam anéis de crescimento visíveis. Com esses dados, ajusta-se uma função para cada árvore, sítio ou parcela amostrada.

Moser e Hall (1969) e Ferreira (1976), consideram como dados ideais para a elaboração de uma função de crescimento, os coletados de maneira contínua nos povoamentos, com as medições praticadas no final dos períodos de crescimento, desde a implantação até a idade de corte, obtendo-se uma série real de crescimento. Para Carmean (1975), os dados obtidos por análise de tronco são os mais apropriados para o desenvolvimento de curvas de índice de sítio. Já uma série de outros autores (BRUCE e SCHUMACHER, 1950; PIENNER e TURNBULL, 1973; SCHNEIDER et al., 1988) empregaram com sucesso dados de unidades temporárias na elaboração de curvas de crescimento em altura.

As curvas de índices de sitio são construídas a partir de equações de índices do local e utilizadas para classificar, de modo quantitativo, a capacidade produtiva do lugar. Essas equações são derivadas de relações funcionais envolvendo a variável dependente altura dominante e a variável independente idade de referência (CAMPOS e LEITE, 2002).

Para Cunha Neto et al. (1996), mais importante que as estatísticas de regressão, particularmente para a elaboração de curvas de índice de sítio, são as análises gráficas dos resíduos que se revestem de grande importância, pois possibilitam identificar se a curva da altura média das árvores dominantes é de fato uma curva média ou apresenta tendência. $\mathrm{O}$ autor ressalta que as curvas monomórficas são todas elaboradas com base nessa curva, e qualquer tendência implica distorção nas curvas limítrofes das classes de sítio a serem estabelecidas.

Os modelos matemáticos empregados para representar as curvas de crescimento, citados na literatura, são muito variados. Entre os mais utilizados estão os de Prodan, Richard's (com dois e três coeficientes), Backman e os de Clutter-Jons (SELLE, 1993).

Neste trabalho, o objetivo principal foi o de construir curvas de índice de sítio, por meio da variável altura dominante e idade, de populações de Hovenia dulcis, definindo entre os modelos de Backman e Richard's, de três coeficientes, o qual descreveu melhor o crescimento nos sítios, com a construção gráfica dos mesmos. 


\section{MATÉRIAL E MÉTODOS}

\section{Localização das áreas de estudo}

O estudo foi realizado em três populações de Hovenia dulcis existentes na Fundação Estadual de Pesquisa Agropecuária - Florestas (FEPAGRO), localizadas sob as coordenadas geográficas de 2940'19" (latitude Sul) e 53⒌'03" (longitude Oeste), conforme Figura 1.

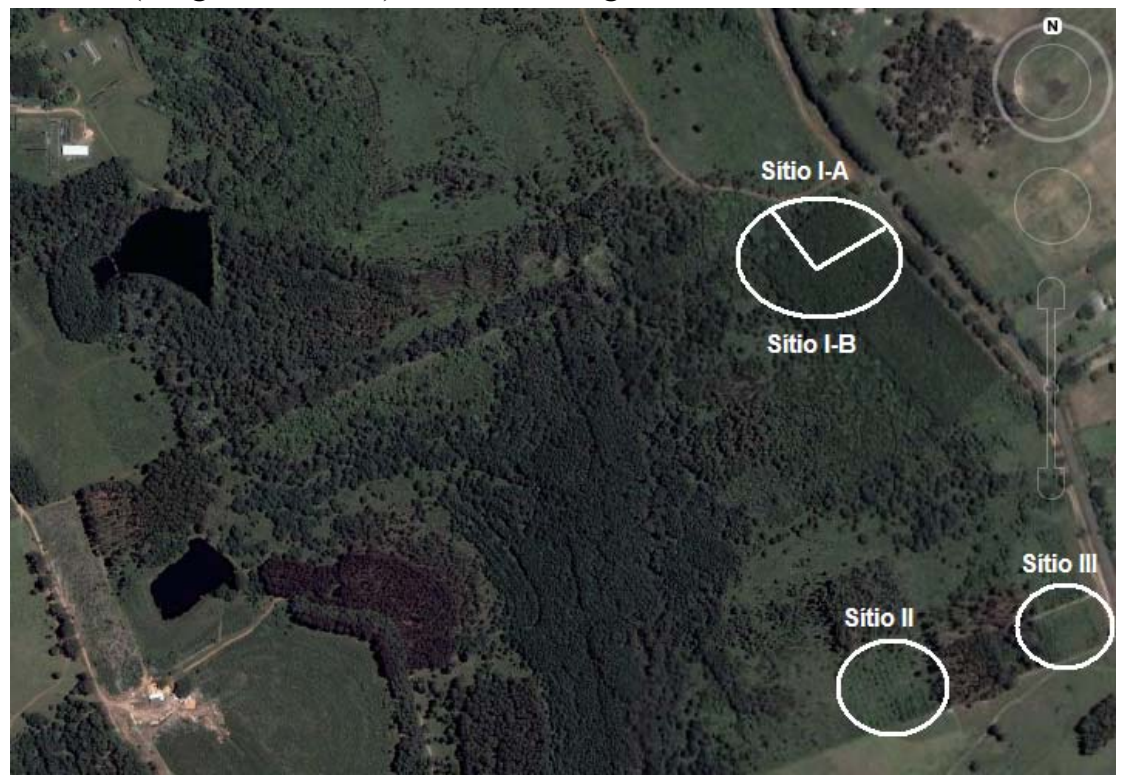

FIGURA 1: Localização das populações de Hovenia dulcis onde foram coletados os dados (Fonte: GOOGLE EARTH, 2008).

FIGURE 1: Location of the populations of Hovenia dulcis where the data were collected (GOOGLE EARTH, 2008).

As populações são florestas plantadas em 1983 e receberam a denominação de Sítio I, II e III, com o Sítio I dividido em "A" e "B". A altitude média do local é de $120 \mathrm{~m}$, e o clima predominante, segundo a classificação de Köpen, é do tipo Cfa, com as temperaturas médias do mês mais frio entre $13^{\circ} \mathrm{C}$ e $18^{\circ} \mathrm{C}$, e do mês mais quente superior a $22^{\circ} \mathrm{C}$, com a média anual também ficando com esse valor. A precipitação pluviométrica no local é em torno dos $1700 \mathrm{~mm}$, distribuídos regularmente durante todo o ano. $\mathrm{O}$ maior número de dias com geada ocorrendo nos meses de junho e julho (MALUF, 2000).

\section{Caracterização dos locais de coleta}

\section{Sítio I}

Esse sítio está acentado sobre um solo Argissolo Vermelho Distrófico Típico, pertencente à unidade de mapeamento São Pedro. São solos que apresentam o horizonte A espesso (em torno de $56 \mathrm{~cm}$ ), de cor bruno-escuro a bruno-avermelhado, franco argilo arenoso, com estrutura fraca em blocos subangulares e com transição clara e plana para o horizonte B (ABRÃO et al., 1988).

Segundo os mesmos autores, na análise física feita no local, foi detectado que a composição granulométrica do solo é composta de 22 a 49 e de 11 a $15 \mathrm{~g} / 100 \mathrm{~g}$ de solo, de argila e silte, respecitvamente, com o solo apresentando uma densidade entre 1,54 e $1,74 \mathrm{~g} / \mathrm{cm}^{3}$ e um pH, em água, que varia de 4,7 a 5,1. Já a análise química demonstrou proporções de fósforo $(\mathrm{P})$ e potássio $(\mathrm{K})$ disponíveis que variam entre 3,4 a 14,9 e de 22 a 76 ppm, respectivamente, com um conteúdo de matéria orgânica, em g/100g de solo, variando de 0,4 a 1,8 .

O terreno onde está acentado o povoamento, que caracteriza esse sítio, apresenta uma variação na declividade, refletindo no desenvolvimento da espécie, com a parte mais elevada tendo um melhor crescimento em altura. A parte mais baixa do terreno, por ter excesso de umidade nas camadas superficiais do solo, tem crescimento menor em altura. As dimensões médias alcançadas, pela espécie nesse sítio, são de $20,5 \mathrm{~cm}$, para o diâmentro e $18 \mathrm{~m}$, para a altura, aos 25 anos. 
O sub-bosque é caracterizado por uma intensa regeneração natural da espécie principal, principalmente onde os espaçamentos são maiores e as alturas das árvores são menores, possibilitando a entrada de grande quantidade de luz pelo dossel. Verifica-se no sub-bosque a presença de um significativo número de outras espécies, como o cedro, a canela, o camboatá-vermelho, o carvalinho, o chal-chal, a mamica-de-cadela, e a pitangueira, entre outras.

\section{Sítio II}

Segundo Abrão et al. (1988), esse sítio apresenta o mesmo tipo de solo, com as mesmas características físicas e composição química do Sítio I, porém, ficou definido que trata-se de um sítio intermediário entre o I e o III. Os aspectos diferenciados são relacionados à drenagem, assemelhando-se muito com o Sítio I-B, apresentando excesso de umidade nas camadas superficiais do solo.

Esse fator possivelmente tenha influenciado o mediano desenvolvimento da espécie, atingindo, na idade de 25 anos, uma altura média de apenas $8 \mathrm{~m}$ e um diâmetro médio de $18 \mathrm{~cm}$. No sub-bosque, podem ser avistadas presenças de espécies arbustivas, alguns exemplares de cedro e uma pequena regeneração da espécie principal.

\section{Sítio III}

Está localizado sobre uma formação Neossolo Litólico Distrófico Fragmentário, em que o horizonte A apresenta espessura aproximada de $30 \mathrm{~cm}$, de coloração bruno-amarelado escuro, franco arenoso a franco argilo arenoso e estrutura fracamente desenvolvida em blocos subangulares, com a transição para o horizonte C ocorrendo abruptamente e a constituição desse horizonte formada de siltitos e argilitos semiintemperizados (ABRÃO et al., 1988).

$\mathrm{Na}$ análise física, a composição granulométria silte e argila foi composta de 10 a 13 e de 17 a 23 $\mathrm{g} / 100 \mathrm{~g}$ de solo, respectivamente, e uma densidade do solo de $1,63 \mathrm{~g} / \mathrm{cm}^{3}$, com um $\mathrm{pH}$, em água, entre 4,7 a 4,8. A análise química realizada em perfil do solo constatou uma quantidade de fósforo e potássio correspondente a 3,4 e $80 \mathrm{ppm}$, respectivamente, com 1,7 a 2,3 g/100g de solo de material orgânico (ABRÃO et al., 1988).

Uma característica visível no local é a condição de baixo desenvolvimento da espécie, ocasionado pela presença de uma camada formada por siltitos e argilitos semi-intemperizados $\left(\mathrm{IIC}_{1}\right)$ acumulando água ferruginosa, de cor amarelo-escura, tóxica para as plantas, condicionando uma baixa estatura das árvores, apenas $6,5 \mathrm{~m}$, e um diâmetro médio de $11 \mathrm{~cm}$, aos 25 anos. $\mathrm{O}$ sub-bosque dessa população não apresenta formação de regeneração natural, apenas gramíneas e pequenos arbustos.

\section{Obtenção dos dados}

Devido a grande variação apresentada no Sítio I, o povoamento sofreu uma divisão baseada na altura dominante (ASSMANN, 1970), calculada para cada parcela do experimento, criando um novo arranjo para o povoamento. Na nova estrutura, foram substituídos os Blocos por Sítios "I-A" e "I-B" conforme Tabela 1 e Figura 2. 
TABELA 1: Reestruturação do experimento com a divisão em dois sítios com base na altura dominante de Assmann de cada parcela.

TABLE 1: Restructuring of the experiment with the division in two ranches with base in the dominant height of Assmann of each portion.

\begin{tabular}{c|c|c|c}
\hline Arranj & Arranjo novo & \multirow{2}{*}{ Espaçamentos } & $\mathrm{h}_{100}(\mathrm{~m})$ \\
\hline Bloco & Sítio & \\
\hline $\mathrm{B}_{1}$ & $\mathrm{I}-\mathrm{A}$ & $4 \times 3$ & 22,6 \\
$\mathrm{~B}_{1}$ & $\mathrm{I}-\mathrm{A}$ & $4 \times 6$ & 22,0 \\
$\mathrm{~B}_{1}$ & $\mathrm{I}-\mathrm{A}$ & $4 \times 5$ & 23,2 \\
$\mathrm{~B}_{1}$ & $\mathrm{I}-\mathrm{A}$ & $4 \times 4$ & 22,9 \\
$\mathrm{~B}_{1}$ & $\mathrm{I}-\mathrm{A}$ & $4 \times 2$ & 20,6 \\
$\mathrm{~B}_{2}$ & $\mathrm{I}-\mathrm{A}$ & $4 \times 5$ & 22,4 \\
$\mathrm{~B}_{2}$ & $\mathrm{I}-\mathrm{A}$ & $4 \times 3$ & 22,7 \\
$\mathrm{~B}_{2}$ & $\mathrm{I}-\mathrm{A}$ & $4 \times 4$ & 24,0 \\
$\mathrm{~B}_{2}$ & $\mathrm{I}-\mathrm{A}$ & $4 \times 6$ & 22,1 \\
$\mathrm{~B}_{2}$ & $\mathrm{I}-\mathrm{B}$ & $4 \times 2$ & 17,9 \\
$\mathrm{~B}_{3}$ & $\mathrm{I}-\mathrm{B}$ & $4 \times 6$ & 19,7 \\
$\mathrm{~B}_{3}$ & $\mathrm{I}-\mathrm{A}$ & $4 \times 4$ & 22,6 \\
$\mathrm{~B}_{3}$ & $\mathrm{I}-\mathrm{A}$ & $4 \times 2$ & 23,1 \\
$\mathrm{~B}_{3}$ & $\mathrm{I}-\mathrm{B}$ & $4 \times 5$ & 20,2 \\
$\mathrm{~B}_{3}$ & $\mathrm{I}-\mathrm{B}$ & $4 \times 3$ & 16,6 \\
$\mathrm{~B}_{4}$ & $\mathrm{I}-\mathrm{B}$ & $4 \times 3$ & 19,1 \\
$\mathrm{~B}_{4}$ & $\mathrm{I}-\mathrm{B}$ & $4 \times 2$ & 18,9 \\
$\mathrm{~B}_{4}$ & $\mathrm{I}-\mathrm{B}$ & $4 \times 4$ & 17,4 \\
$\mathrm{~B}_{4}$ & $\mathrm{I}-\mathrm{B}$ & $4 \times 5$ & 17,3 \\
$\mathrm{~B}_{4}$ & $\mathrm{I}-\mathrm{B}$ & $4 \times 6$ & 17,5 \\
\hline
\end{tabular}
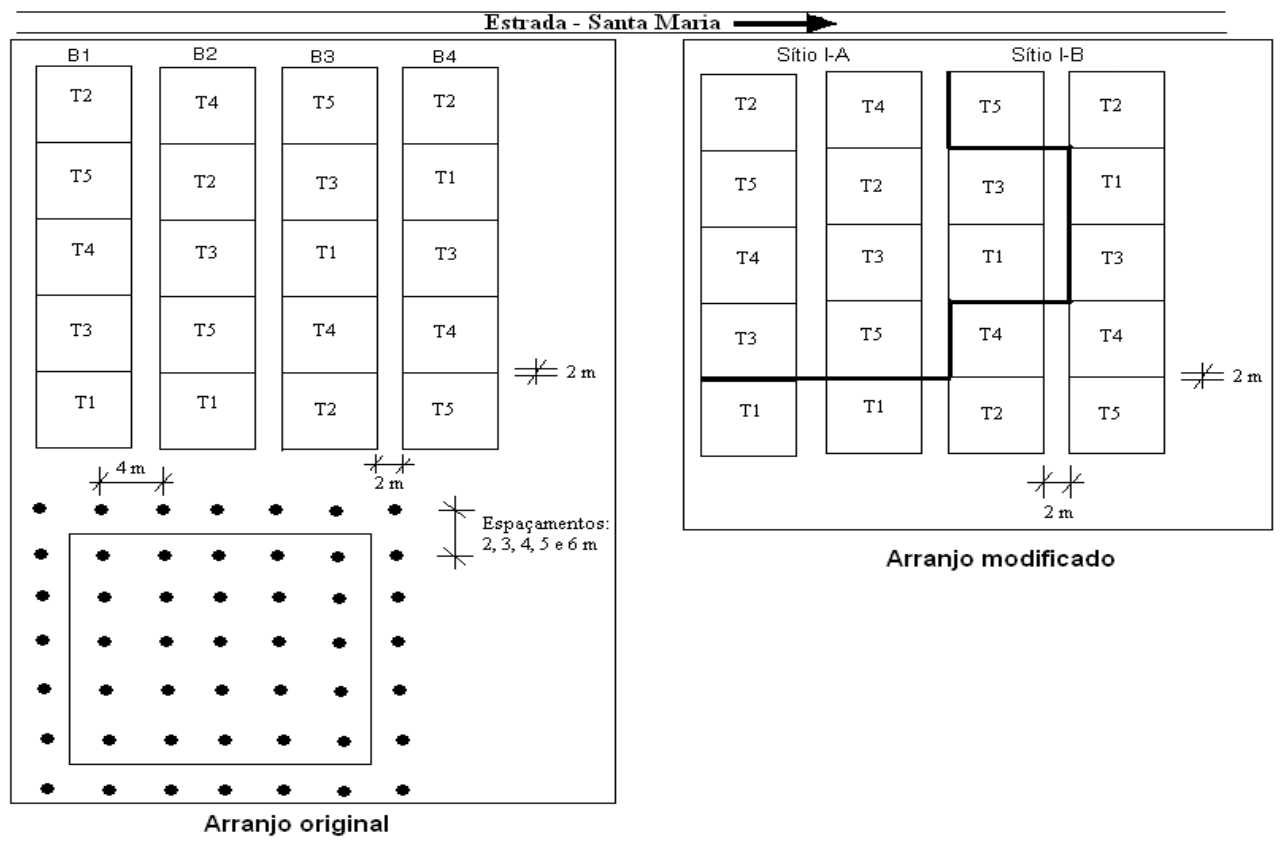

Arranjo modificado

FIGURA 2: Arranjo inicial e reestruturação da população do Sítio I, de Hovenia dulcis, Santa Maria, RS.

FIGURE 2: Arrangement initial and restructuring of Site I population, of Hovenia dulcis, Santa Maria, RS.

Tendo a relação das alturas dominantes dos sítios, foi selecionada uma árvore de cada faixa de altura dominante para ser abatida e analisado o seu tronco, obedecendo à metodologia descrita por Finger (1992).

Foram abatidas árvores pertencentes as seguintes classes de altura dominante:

Sítio I-A: coleta de 3 árvores na classe de altura de 20 a 22 m e 3 na classe de 22 a 24 m; 
Sítio I-B: coleta de 3 árvores na classe de altura de 16 a $18 \mathrm{~m}$ e 3 na classe de 18 a $20 \mathrm{~m}$.

Sítio II: coleta de 3 árvores na classe de altura de 10 a $12 \mathrm{~m}$;

Sítio III: coleta de 3 árvores na classe de altura de 8 a $10 \mathrm{~m}$.

Após, foram abatidas as árvores e retiradas as fatias, com aproximadamente $5 \mathrm{~cm}$ de espessura, nas alturas de $0,2 \mathrm{~m} ; 0,7 \mathrm{~m} ; 1,3 \mathrm{~m}$ e, a partir deste ponto, de $2 \mathrm{em} 2$ metros até atingir a altura total da árvore. Quando o ponto a ser retirada a fatia coincidisse com inserção de galhos, o mesmo era deslocado para posição dos entre-nós. Na sequência, as fatias foram deixadas ao ar livre para perder o excesso de umidade e, após secas em estufa e posteriormente lixadas. Em seguida, foram demarcados os raios e anéis para a medição no aparelho LINTAB $^{\mathrm{TM}}$ (2000) conectado a um ordenador com software Time Series Analisys Program (TSAP ${ }^{\mathrm{TM}}, 2000$ ), do Laboratório de Manejo Florestal do Departamento de Ciências Florestais da UFSM.

A medição dos anéis, sobre as fatias, foi realizada sob 4 raios, com a definição desses seguindo a metodologia descrita por Selle et al. (2008). O primeiro raio foi definido com desvio de $45^{\circ}$ em relação ao maior raio da secção, no sentido horário. O prolongamento deste em direção oposta, a partir da medula até a casca, define o terceiro raio. O segundo e o quarto raio ficam definidos com uma reta que passa pela medula da árvore com ângulo de $90^{\circ}$ em relação aos raios um e três.

Para a obtenção do valor do crescimento daquele anel (que corresponde a um ano de crescimento da árvore), calculou-se a média aritmética entre os quatro valores medidos do respectivo anel de crescimento.

Após a leitura dos anéis e raios, os dados foram gravados em um arquivo de dados e, posteriormente processados, onde se obteve a idade das árvores relacionadas à altura e ao diâmetro.

\section{Definição do modelo matemático}

A seleção do modelo para elaboração das curvas índice de sítio foi entre as funções de Backman (1943) e Richard's (1959) com três coeficientes, ajustando-os para cada árvore, o que gerou 36 regressões.

Sobre as estatísticas oriundas das regressões foi efetuado um ranqueamento para definir qual dos modelos ajustou melhor aos dados. Para isso foram atribuídos valores ponderados para os modelos, em cada estatística, onde 1 foi dado para a melhor estatística e 2 para a pior. A soma desses valores vai definiu o valor ponderado que, quanto menor, indica que o modelo é melhor.

\section{Comparação do crescimento em altura entre os sítios}

Para comparar o desenvolvimento em altura das árvores, nas diferentes idades e locais estudados, os dados foram submetidos a uma análise de covariância, utilizando para isso o modelo de Backman. Com isso definiu-se quantos conjuntos de curvas índices deveriam ser construídas.

\section{Processamentos dos dados}

Para ajustar as regressões lineares, foram utilizados procedimentos como: PROC STEPWISE, PROC CORR, PROC GLM e PROC REG. Já as não-lineares, foram analisadas pelo procedimento PROC NLIN no método MARQUARDT, todos do pacote Statistical Analysis System (SAS, 1999). Para os demais cálculos, foi empregada a planília eletrônica Microsoft ${ }^{\circledR}$ Oficce EXCEL (2003).

\section{RESULTADOS E DISCUSSÃO}

\section{Definição do modelo matemático}

Inicialmente plotou-se os dados observados de altura em função da idade, das 18 árvores, provenientes das análises de tronco realizadas nos povoamentos Sítios I-A, I-B, II e III, conforme demonstrados na Figura 3. 


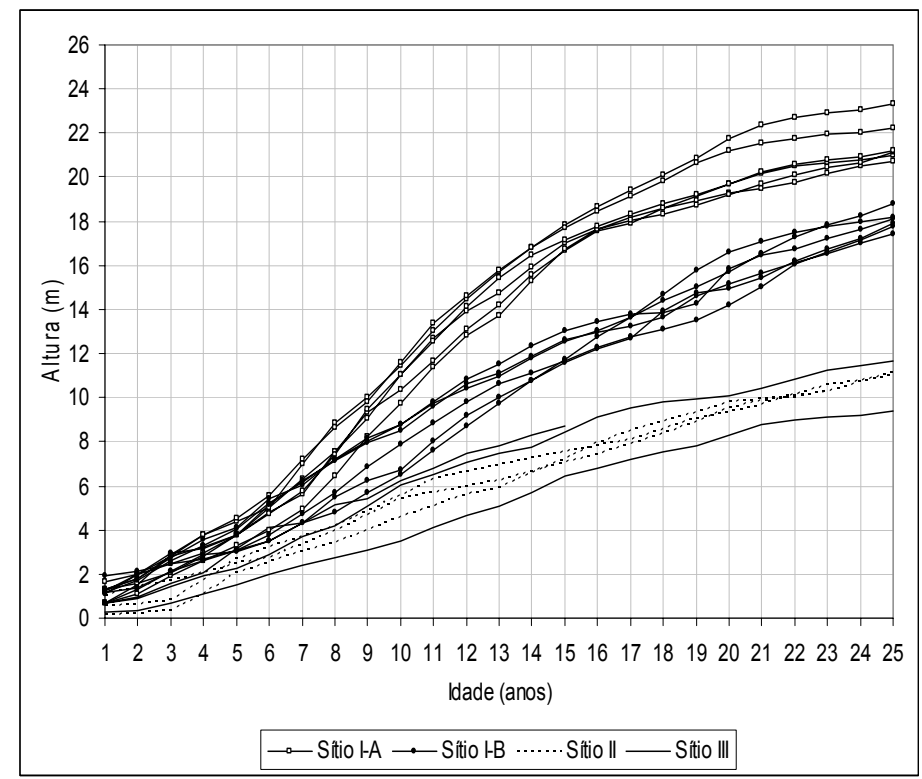

FIGURA 3: Árvores dominantes de Hovenia dulcis amostradas por análise de tronco.

FIGURE 3: Dominant trees of Hovenia dulcis date for log analysis.

Observa-se na Figura 3 que, nos três primeiros anos de crescimento do povoamento, ocorre uma instabilidade nas curvas, com as árvores do Sítio I-B tendo desenvolvimento superior ao do Sítio I-A. Esse resultado provavelmente se deve as árvores estarem localizadas onde o lençol freático é mais superficial, possibilitando desta forma o maior desenvolvimento das mesmas. Porém, quando as raízes dessas árvores atingiram o lençol freático, ocorreu uma desaceleração no crescimento. Já no Sítio I-A, por estar localizado onde o lençol é mais profundo, teve um maior desenvolvimento.

O procedimento de seleção entre os modelos de Backman (1943) e Richard's (1959) com três coeficientes, foi ajustado para cada árvore, gerando 36 análises de variância , conforme demonstrado na Tabela 2.

TABELA 2: Resultados estatísticos obtidos no ajuste dos modelos de Backman e Richard's de três coeficientes para cada árvore.

TABLE 2: Results statisticians obtained in the adjustment of the models of Backman and Richard's of three coefficients for each tree.

\begin{tabular}{cc|c|c|c|r|rrrrr}
\hline \multirow{2}{*}{ Sítio } & \multirow{2}{*}{ Árvore } & \multicolumn{5}{|c|}{ Backman } & \multicolumn{4}{c}{ Richard's com 3 coeficientes } \\
\cline { 3 - 10 } & & $\mathrm{R}_{\text {Aiust. }}$ & Syx & CV\% & $\mathrm{F}$ & $\mathrm{R}_{\text {Aiust. }}^{2}$ & Syx & CV\% & \multicolumn{1}{c}{$\mathrm{F}$} \\
\hline I-A & 1 & 0,99 & 0,04 & 1,27 & 1636,21 & 0,99 & 0,31 & 2,13 & 17889,50 \\
\hline I-A & 2 & 0,99 & 0,05 & 2,19 & 1087,83 & 0,99 & 0,34 & 2,36 & 14995,00 \\
\hline I-A & 3 & 0,99 & 0,05 & 1,92 & 945,03 & 0,99 & 0,36 & 2,43 & 13766,90 \\
\hline I-A & 4 & 0,99 & 0,04 & 1,73 & 1369,00 & 0,99 & 0,29 & 1,93 & 21214,40 \\
\hline I-A & 5 & 0,99 & 0,02 & 0,67 & 8705,99 & 0,99 & 0,19 & 1,18 & 58885,40 \\
\hline I-A & 6 & 0,99 & 0,03 & 1,10 & 2672,09 & 0,99 & 0,26 & 1,63 & 29552,00 \\
\hline I-B & 1 & 0,99 & 0,03 & 1,45 & 2278,26 & 0,99 & 0,39 & 3,52 & 6425,03 \\
\hline I-B & 2 & 0,99 & 0,02 & 0,94 & 3503,06 & 0,99 & 0,22 & 1,87 & 21749,00 \\
\hline I-B & 3 & 0,99 & 0,02 & 0,97 & 3294,56 & 0,99 & 0,33 & 2,72 & 10691,90 \\
\hline I-B & 4 & 0,99 & 0,03 & 1,46 & 2802,45 & 0,99 & 0,19 & 1,67 & 30296,90 \\
\hline I-B & 5 & 0,99 & 0,05 & 2,15 & 1288,94 & 0,99 & 0,28 & 2,57 & 12959,20 \\
\hline I-B & 6 & 0,99 & 0,02 & 0,98 & 3289,41 & 0,99 & 0,32 & 2,61 & 11784,40 \\
\hline II & 1 & 0,99 & 0,04 & 2,46 & 1680,56 & 0,99 & 0,21 & 3,39 & 7353,79 \\
\hline II & 2 & 0,99 & 0,02 & 1,54 & 1959,94 & 0,99 & 0,21 & 2,86 & 9747,65 \\
\hline II & 3 & 0,99 & 0,03 & 1,80 & 2420,66 & 0,99 & 0,21 & 3,01 & 9201,41 \\
\hline III & 1 & 0,99 & 0,04 & 2,56 & 1741,41 & 0,99 & 0,18 & 3,04 & 8353,70 \\
\hline III & 2 & 0,99 & 0,03 & 1,82 & 515,31 & 0,99 & 0,15 & 2,45 & 6533,56 \\
\hline III & 3 & 0,99 & 0,02 & 1,21 & 3965,79 & 0,99 & 0,17 & 2,16 & 16576,60 \\
\hline
\end{tabular}

Sendo: $\mathrm{CV} \%=$ coeficiente de variação em percentagem; $\mathrm{R}_{\text {Ajust. }}^{2}=$ coeficiente de determinação ajustado; Syx $=$ erro padrão da estimativa; $\mathrm{F}$ = valor de $\mathrm{F}$ da análise de variância. 
Sobre as estatísticas da Tabela 2 efetuou-se um ranqueamento para definir qual dos modelos ajustou melhor aos dados. Para isso foi atribuido valores ponderados para os modelos, em cada estatística, onde o valor 1 foi dado para a melhor estatística e o valor 2 para a pior. A soma desses valores definiu o valor ponderado que, quanto menor indica que o modelo é melhor, conforme demonstrado na Tabela 3.

Analisando a Tabela 3 constata-se que o modelo de Backman apresenta os menores valores ponderados e, consequentemente é o modelo mais preciso para expressar os crescimentos nos diferentes locais.

TABELA 3: Valores ponderados das estatísticas obtidos no ajuste dos modelos de Backman e Richard's de três coeficientes para cada sítio.

TABLE 3: Considered values of the statistics obtained in the adjustment of the models of Backman and Richard's of three coefficients to each ranch.

\begin{tabular}{|c|c|c|c|c|c|c|c|c|c|c|c|}
\hline \multirow{2}{*}{ Sítio } & \multirow{2}{*}{ Árvore } & \multicolumn{5}{|c|}{ Backman } & \multicolumn{5}{|c|}{ Richard's com 3 coeficientes } \\
\hline & & $\mathrm{R}^{2}$ Ajust. & Syx & $\mathrm{CV} \%$ & $\mathrm{~F}$ & VP & $\mathrm{R}_{\text {Ajust. }}^{2}$ & Syx & $\mathrm{CV} \%$ & $\mathrm{~F}$ & VP \\
\hline $\mathrm{I}-\mathrm{A}$ & 1 & 1 & 1 & 1 & 2 & 5 & 1 & 2 & 2 & 1 & 6 \\
\hline $\mathrm{I}-\mathrm{A}$ & 2 & 1 & 1 & 1 & 2 & 5 & 1 & 2 & 2 & 1 & 6 \\
\hline I-A & 3 & 1 & 1 & 1 & 2 & 5 & 1 & 2 & 2 & 1 & 6 \\
\hline $\mathrm{I}-\mathrm{A}$ & 4 & 1 & 1 & 1 & 2 & 5 & 1 & 2 & 2 & 1 & 6 \\
\hline I-A & 5 & 1 & 1 & 1 & 2 & 5 & 1 & 2 & 2 & 1 & 6 \\
\hline $\mathrm{I}-\mathrm{A}$ & 6 & 1 & 1 & 1 & 2 & 5 & 1 & 2 & 2 & 1 & 6 \\
\hline I-B & 1 & 1 & 1 & 1 & 2 & 5 & 1 & 2 & 2 & 1 & 6 \\
\hline $\mathrm{I}-\mathrm{B}$ & 2 & 1 & 1 & 1 & 2 & 5 & 1 & 2 & 2 & 1 & 6 \\
\hline $\mathrm{I}-\mathrm{B}$ & 3 & 1 & 1 & 1 & 2 & 5 & 1 & 2 & 2 & 1 & 6 \\
\hline I-B & 4 & 1 & 1 & 1 & 2 & 5 & 1 & 2 & 2 & 1 & 6 \\
\hline I-B & 5 & 1 & 1 & 1 & 2 & 5 & 1 & 2 & 2 & 1 & 6 \\
\hline I-B & 6 & 1 & 1 & 1 & 2 & 5 & 1 & 2 & 2 & 1 & 6 \\
\hline II & 1 & 1 & 1 & 1 & 2 & 5 & 1 & 2 & 2 & 1 & 6 \\
\hline II & 2 & 1 & 1 & 1 & 2 & 5 & 1 & 2 & 2 & 1 & 6 \\
\hline II & 3 & 1 & 1 & 1 & 2 & 5 & 1 & 2 & 2 & 1 & 6 \\
\hline III & 1 & 1 & 1 & 1 & 2 & 5 & 1 & 2 & 2 & 1 & 6 \\
\hline III & 2 & 1 & 1 & 1 & 2 & 5 & 1 & 2 & 2 & 1 & 6 \\
\hline III & 3 & 1 & 1 & 1 & 2 & 5 & 1 & 2 & 2 & 1 & 6 \\
\hline
\end{tabular}

Sendo: $\mathrm{CV} \%=$ coeficiente de variação em percentagem; $\mathrm{R}_{\mathrm{Ajust}}=$ coeficiente de determinação ajustado; Syx $=$ erro padrão da estimativa; $\mathrm{F}$ = valor de $\mathrm{F}$ da análise de variância; $\mathrm{VP}$ = valor ponderado.

\section{Comparação do crescimento em altura entre os sítios}

Para comparar o desenvolvimento em altura das árvores, nas diferentes idades e locais estudados, os dados foram submetidos a uma análise de covariância, utilizando para isso o modelo de Backman.

(Tabela 4).

Inicialmente a verificação do comportamento foi efetuada para o teste de tendência ou inclinação 
TABELA 4: Análise de covariância, para teste de tendência, entre os sítios de Hovenia dulcis.

TABLE 4: Covariância analysis, for tendency test, among the ranches of Hovenia dulcis.

\begin{tabular}{|c|c|c|c|c|c|}
\hline $\mathrm{FV}$ & $\mathrm{GL}$ & SQ & QM & $\mathrm{F}$ & Prob. $>\mathrm{F}$ \\
\hline Modelo & 11 & 125,53 & 11,41 & 879,11 & $<0,0001$ \\
\hline $\operatorname{Ln}(t)$ & 1 & 3,49 & 3,49 & 268,58 & $<0,0001$ \\
\hline $\operatorname{Ln}^{2}(\mathrm{t})$ & 1 & 1,22 & 1,22 & 94,31 & $<0,0001$ \\
\hline Sítio & 3 & 0,27 & 0,09 & 6,62 & 0,0002 \\
\hline $\operatorname{Ln}(\mathrm{t}) \times$ Sítio & 3 & 0,41 & 0,14 & 10,60 & $<0,0001$ \\
\hline $\operatorname{Ln}^{2}(\mathrm{t}) \times$ Sítio & 3 & 0,39 & 0,13 & 10,01 & $<0,0001$ \\
\hline Resíduo & 356 & 4,62 & 0,01 & - & - \\
\hline Total & 367 & 130,15 & - & - & - \\
\hline Parâmetro & & $\mathrm{VE}$ & Erro & $\mathrm{Vt}$ & $\operatorname{Pr}>|t|$ \\
\hline \multicolumn{2}{|c|}{$\operatorname{Ln}(\mathrm{t}) *$ Sítio I-A x $\operatorname{Ln}(\mathrm{t}) *$ Sítio I-B } & 1,682397628 & 0,34372424 & 4,89 & $<0,0001$ \\
\hline \multicolumn{2}{|c|}{$\operatorname{Ln}(\mathrm{t}) *$ Sítio I-A x Ln(t)*Sítio II } & 1,871501327 & 0,42097450 & 4,45 & $<0,0001$ \\
\hline \multicolumn{2}{|c|}{$\operatorname{Ln}(\mathrm{t}) *$ Sítio I-A x Ln $(\mathrm{t}) *$ Sítio III } & 1,366866969 & 0,43605686 & 3,13 & 0,0019 \\
\hline \multicolumn{2}{|c|}{$\operatorname{Ln}(\mathrm{t}) *$ Sítio I-B $x \operatorname{Ln}(\mathrm{t}) *$ Sítio II } & $-0,189103699$ & 0,42097450 & $-0,45$ & 0,6536 \\
\hline \multicolumn{2}{|c|}{$\operatorname{Ln}(\mathrm{t}) *$ Sítio I-B $x \operatorname{Ln}(\mathrm{t}) *$ Sítio III } & $-0,315530659$ & 0,43605686 & $-0,72$ & 0,4698 \\
\hline \multicolumn{2}{|c|}{$\operatorname{Ln}(\mathrm{t}) *$ Sítio II x Ln(t)*Sítio III } & $-0,504634358$ & 0,49921815 & $-1,01$ & 0,3128 \\
\hline
\end{tabular}

Sendo: $L n=$ logaritmo natural; $t=$ idade (anos); FV = fonte de variação; GL = graus de liberdade; $\mathrm{SQ}=\mathrm{soma}$ dos quadrados; $\mathrm{QM}=$ quadrado médio; $\mathrm{VE}=$ valor estimado; $\mathrm{Vt}=$ valor da estatística $t ; \mathrm{F}=$ valor de $F$ calculado para a variável dependente; Prob. $>\mathrm{F}=$ nível de probabilidade de erro.

$\mathrm{Na}$ análise de covariância constante da Tabela 4, ao considerar um nível de significância de $1 \%$ do erro, é demonstrado que não existe diferença significativa entre os Sítios I-B, II e III. Assim, a hipótese de igualdade de inclinação entre todas as curvas de crescimento é rejeitada, ocorrendo somente à mesma inclinação entre os Sítios I-B, II e III, com a existência de paralelismo entre elas. Em função disso, foi necessário proceder a uma nova análise de covariância entre esses locais (Tabela 5). No Sítio I-A ficou definido a necessidade da confecção de um conjunto específico de curvas.

TABELA 5: Análise de covariância, para teste de nível, entre os Sítios I-B, II e III de Hovenia dulcis.

TABLE 5: Covariância analysis, for level test, among the Sites I-B, II and III of Hovenia dulcis.

\begin{tabular}{lrrrrrr}
\hline FV & GL & SQ & QM & F & Prob. $>$ F \\
\hline Modelo & 4 & 70,71 & 17,68 & 1036,28 & $<0,0001$ \\
Ln(t) & 1 & 1,81 & 1,81 & 103,97 & $<0,0001$ \\
Ln $^{2}(\mathrm{t})$ & 1 & 0,48 & 0,48 & 27,48 & $<0,0001$ \\
Sítio & 2 & 15,41 & 15,41 & 886,06 & $<0,0001$ \\
Resíduo & 237 & 4,04 & 0,02 & - & - \\
Total & 241 & 74,76 & - & - & - \\
\hline Parâmetro & \multicolumn{7}{c}{ VE } & 0,474102341 & 0,02143513 & 22,12 & $<0,0001$ \\
\hline Sítio I-B x Sítio II & & 0,531666860 & 0,02015392 & 26,38 & $<0,0001$ \\
\hline Sítio I-B x Sítio III & & $-0,057564519$ & 0,02438972 & $-2,36$ & 0,0191 \\
\hline Sítio II x Sítio III & & & & & \\
\hline
\end{tabular}

Sendo: $L n=$ logaritmo natural; $t=$ idade (anos); $\mathrm{FV}=$ fonte de variação; $\mathrm{GL}=$ graus de liberdade; $\mathrm{SQ}=$ soma dos quadrados; $\mathrm{QM}=$ quadrado médio; $\mathrm{VE}=$ valor estimado; $\mathrm{Vt}=$ valor da estatística $t ; \mathrm{F}=$ valor de $F$ calculado para a variável dependente; Prob. $>\mathrm{F}$ = nível de probabilidade de erro.

Ao realizar o teste de covariância (Tabela 5) com objetivo de verificação dos níveis entre os Sítios IB, II e III, para uma probabilidade de erro de 5\%, constatou-se não haver diferença significativa entre eles. Portanto foi necessário apenas um conjunto de curvas índice de sítio para representá-las.

Assim sendo, as análises de covariâncias comprovaram a necessidade de ajustar duas equações para a confecção das curvas índice de sítio para Hovenia dulcis, dos locais estudados, uma para o Sítio I-A e outra para a união dos Sítios I-B+II+III.

O mesmo não ocorreu no estudo realizado por Selle (1993), ao definir índices de sítios para Pinus taeda, oriundos de três locais distintos da região de Cambará do Sul, RS. O autor observou a necessidade de construir somente um conjunto de curvas índice, o que não ocorreu com o estudo de Tonini (2000). Para classificar sítios com Pinus elliottii, de três locais do Rio Grande do Sul, Tonini (2000), constatou que a 
hipótese de paralelismo entre as curvas de crescimento deveria ser rejeitada, necessitando elaborar um conjunto de curvas índice para cada local estudado.

Já no estudo de Drescher (2004), foi necessário apenas um conjunto de curvas índice de sítio para Tectona grandis, oriundas de dois locais no estado do Mato Grosso.

Os ajustes das equações que representam os crescimentos nos dois conjuntos de dados, definidos como semelhantes (Sítios I-A e I-B+II+III), são apresentadas na Tabela 6.

TABELA 6: Estatísticas referentes aos ajustes das equações para os Sítios de Hovenia dulcis.

TABLE 6: Statistics regarding the fittings of the equations to the sites of Hovenia dulcis.

\begin{tabular}{|c|c|c|c|c|c|c|}
\hline \multirow{2}{*}{ Sítio } & \multirow{2}{*}{ Equação } & \multicolumn{5}{|c|}{ Estatística } \\
\hline & & $\mathrm{R}^{2}$ & Syx & $\mathrm{CV} \%$ & $\mathrm{~F}$ & $\operatorname{Pr}>F$ \\
\hline $\mathrm{I}-\mathrm{A}$ & $\ln \left(\mathrm{h}_{100}\right)=-3,32121+3,71347 \ln (\mathrm{t})-0,53500 \ln ^{2}(\mathrm{t})$ & 0,98 & 0,07 & 2,75 & 3142,51 & $<0,0001$ \\
\hline $\mathrm{I}-\mathrm{B}+\mathrm{II}+\mathrm{III}$ & $\ln \left(\mathrm{h}_{100}\right)=-1,69260+1,97756 \ln (\mathrm{t})-0,19360 \ln ^{2}(\mathrm{t})$ & 0,74 & 0,28 & 13,66 & 337,59 & $<0,0001$ \\
\hline
\end{tabular}

Sendo: $h_{100}=$ altura dominante $(\mathrm{m}) ; \ln =\operatorname{logaritmo}$ natural; $t=$ idade $(\operatorname{anos}) ; \mathrm{R}^{2}=$ coeficiente de determinação; Syx $=$ erro padrão da estimativa; $\mathrm{CV} \%=$ coeficiente de variação em percentagem; $\mathrm{F}=$ valor de $\mathrm{F}$ da análise de variância.

Observa-se na Tabela 6 que o modelo se ajusta melhor ao conjunto de dados representativos do Sítio I-A, apresentando todas as estatísticas superiores ao outro grupo de locais estudados. $\mathrm{O}$ fator determinante para que o ajuste tenha muita precisão nos Sítios I-B, II e III é devido a grande amplitude de variação das alturas dos povoamentos nesses locais, refletindo nos dados coletados, porém mesmo assim o ajuste foi considerado bom.

De acordo com Selle (1993) e Tonini (2000) a utilização do modelo de Richard's, com três parâmetros, na construção de índices de sítio, apresentaram ajustes muito parecidos, com valores para os coeficientes de determinação superiores a $99 \%$.

Já Drescher (2004), em seu estudo empregou o modelo de Richard's, porém com dois coeficientes, com o ajuste explicando $70 \%$ da variação total dos dados.

Outro modelo bastante empregado para estimar crescimentos é o de Backman et al. (2000) e Scheren et al. (2003), nos estudos de tendências de crescimento em diâmetro, volume comercial, incremento corrente anual do volume comercial e fator de forma comercial, para Tabebuia impetiginosa e Ocotea pulchella, na região central do Rio Grande do Sul, o empregaram com excelentes ajustes.

A função de Backman também foi utilizada por Floriano et al. (2006), para descrever o crescimento em altura de Pinus elliottii, com 18 anos, oriundos do município de Piratini, no Rio Grande do Sul, perfazendo um ajuste para o coeficiente de determinação de $83 \%$. Outro trabalho a utilizar o modelo de Backman foi Hess (2006), para descrever o crescimento em volume sem casca e a altura em função da idade de Araucaria angustifolia, em três regiões fitogeográficas do Rio Grande do Sul, onde constatou que o coeficiente de determinação tinha uma precisão superior a $92 \%$.

\section{Confecção das curvas índice de sítio}

Para a elaboração dos dois conjuntos de curvas índice de sítio, inicialmente definiu-se a idade índice como a própria idade do povoamento, 25 anos.

Em função da instabilidade constatada nos primeiros quatro anos, provocada pelos fatores anteriormente citados, e da faixa de idade do povoamento, definiu-se que as curvas índice de sítio devem ser traçadas entre as idades de 5 e 25 anos, com intervalo entre as classes de sítio de 2 metros.

Assim sendo, com os modelos que descrevem os dois locais e, variando a idade de 5 a 25 anos, se obteve as curvas guia ou mestra, para ambos os sítios estudados (Figura 4). 


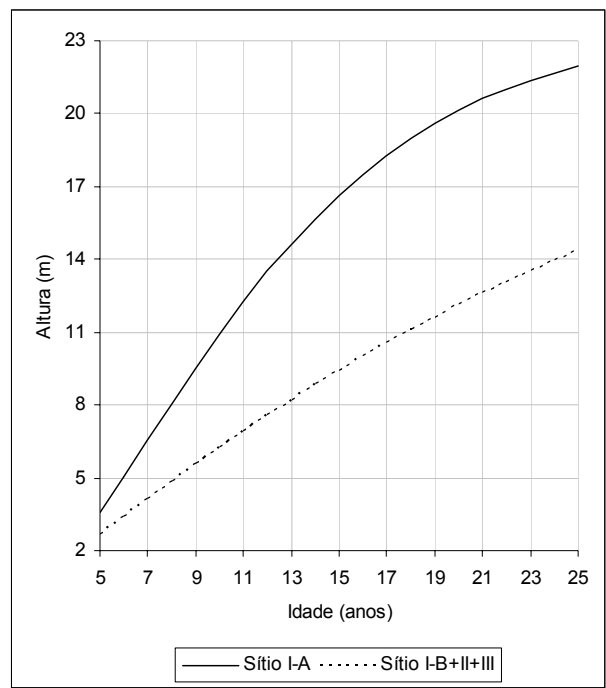

FIGURA 4: Curvas guia traçadas com o modelo de Backman para os sítios estudados.

FIGURE 4: Curves guide traced with the model of Backman to the studied sites.

Analisando a Figura 4, a curva guia ajustada para o Sítio I-A segue tendência parabolóide, com a concavidade voltada para baixo, enquanto que para o Sítio I-B+II+III apresenta tendência seguida é próxima à linear. No primeiro caso, está indicando que o crescimento já está próximo da assintota, ou seja, no limite do sítio. No segundo sítio, este ponto ainda não foi atingido, necessitando coletar árvores de maior idade para poder definir, ou esperar que o povoamento alcance tal idade.

Após a construção das curvas guias ou mestras, foram elaboradas as demais curvas índice de sítio, por derivação dessas, utilizando um dos métodos citados por Selle et al. (2008), cujos resultados estão apresentados na Tabela 7 e nas Figuras 5 e 6.

TABELA 7: Valores das curvas índice de sítio para Hovenia dulcis de dois locais (Sítio I-A e Sítio I-B+II+III) localizados na região central do estado do Rio Grande do Sul, Brasil.

TABLE 7: Values of the curves ranch index for Hovenia dulcis of two places (Site I-A and Site I-B+II+III) located in the central area of the state of Rio Grande do Sul, Brazil.

\begin{tabular}{c|c|c|c|c|c|c|c|c|c}
\hline \multirow{2}{*}{$\begin{array}{c}\text { Idade } \\
\text { (anos) }\end{array}$} & \multicolumn{8}{|c|}{ Índice de sítio por local } \\
\cline { 2 - 10 } & 8 & 10 & 12 & 14 & 16 & 18 & 20 & 22 & 24 \\
\hline 5 & 1,5 & 1,9 & 2,2 & 2,6 & 3,0 & 3,4 & 3,2 & 3,6 & 3,9 \\
6 & 1,9 & 2,4 & 2,8 & 3,3 & 3,8 & 4,3 & 4,6 & 5,0 & 5,5 \\
7 & 2,3 & 2,9 & 3,5 & 4,0 & 4,6 & 5,2 & 6,0 & 6,6 & 7,2 \\
8 & 2,7 & 3,4 & 4,1 & 4,7 & 5,4 & 6,1 & 7,3 & 8,1 & 8,8 \\
9 & 3,1 & 3,9 & 4,6 & 5,4 & 6,2 & 7,0 & 8,7 & 9,6 & 10,4 \\
10 & 3,5 & 4,3 & 5,2 & 6,1 & 7,0 & 7,8 & 10,0 & 11,0 & 12,0 \\
11 & 3,9 & 4,8 & 5,8 & 6,7 & 7,7 & 8,7 & 11,2 & 12,3 & 13,4 \\
12 & 4,2 & 5,3 & 6,3 & 7,4 & 8,4 & 9,5 & 12,3 & 13,5 & 14,8 \\
13 & 4,6 & 5,7 & 6,8 & 8,0 & 9,1 & 10,3 & 13,3 & 14,7 & 16,0 \\
14 & 4,9 & 6,1 & 7,4 & 8,6 & 9,8 & 11,0 & 14,3 & 15,7 & 17,2 \\
15 & 5,2 & 6,5 & 7,9 & 9,2 & 10,5 & 11,8 & 15,2 & 16,7 & 18,2 \\
16 & 5,6 & 6,9 & 8,3 & 9,7 & 11,1 & 12,5 & 15,9 & 17,5 & 19,1 \\
17 & 5,9 & 7,3 & 8,8 & 10,3 & 11,7 & 13,2 & 16,6 & 18,3 & 20,0 \\
18 & 6,2 & 7,7 & 9,2 & 10,8 & 12,3 & 13,9 & 17,3 & 19,0 & 20,7 \\
19 & 6,4 & 8,1 & 9,7 & 11,3 & 12,9 & 14,5 & 17,8 & 19,6 & 21,4 \\
20 & 6,7 & 8,4 & 10,1 & 11,8 & 13,5 & 15,1 & 18,3 & 20,2 & 22,0 \\
21 & 7,0 & 8,7 & 10,5 & 12,2 & 14,0 & 15,7 & 18,8 & 20,7 & 22,5 \\
22 & 7,3 & 9,1 & 10,9 & 12,7 & 14,5 & 16,3 & 19,2 & 21,1 & 23,0 \\
23 & 7,5 & 9,4 & 11,3 & 13,2 & 15,0 & 16,9 & 19,5 & 21,4 & 23,4 \\
24 & 7,8 & 9,7 & 11,6 & 13,6 & 15,5 & 17,5 & 19,8 & 21,7 & 23,7 \\
25 & 8,0 & 10,0 & 12,0 & 14,0 & 16,0 & 18,0 & 20,0 & 22,0 & 24,0 \\
\hline
\end{tabular}




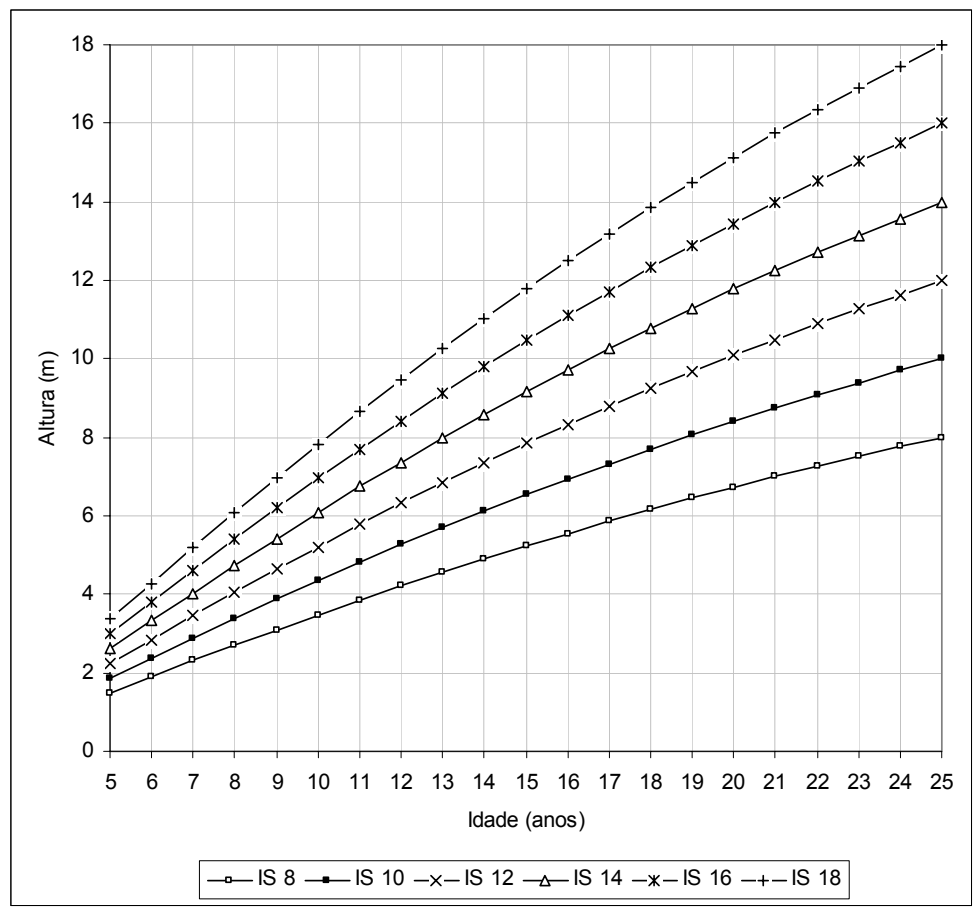

FIGURA 5: Curvas índice de sítio para Hovenia dulcis do Sítio I-B+II+III, localizado na região central do estado do Rio Grande do Sul, Brasil.

FIGURE 5: Curves ranch index for Hovenia dulcis of the Síte I-B+II+III, located in the central area of the state of Rio Grande do Sul, Brazil.

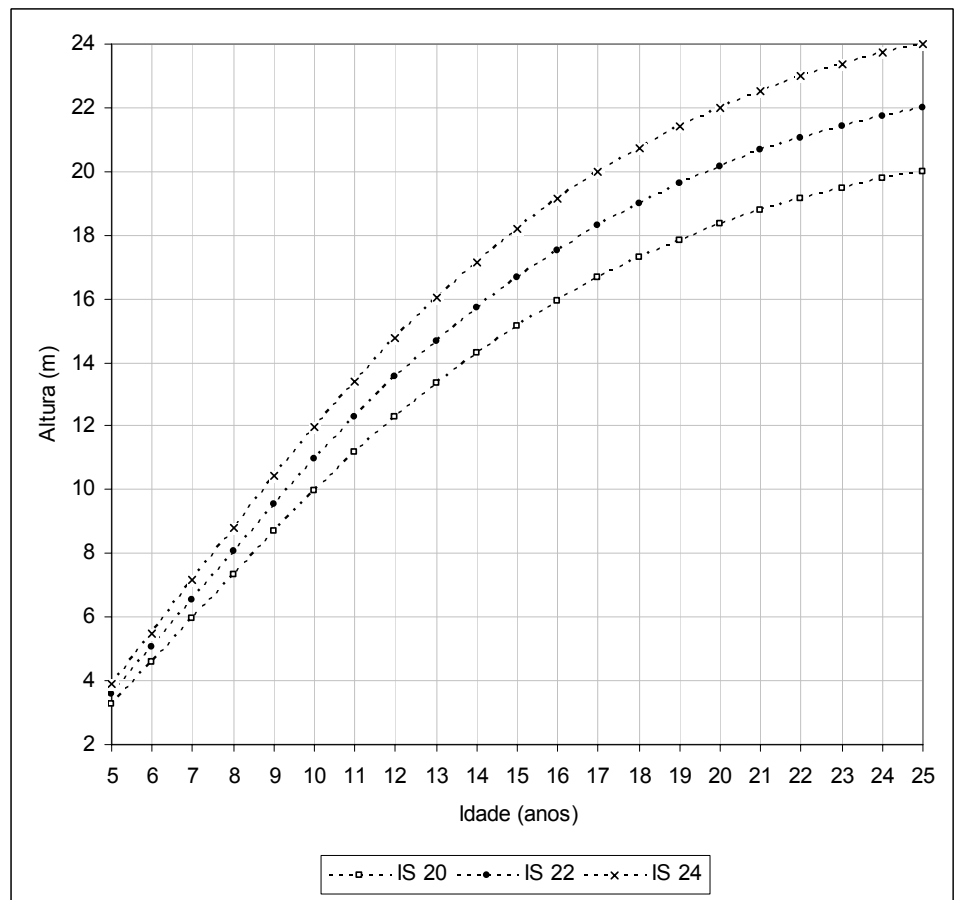

FIGURA 6: Curvas índice de sítio para Hovenia dulcis do Sítio I-A, localizado na região central do estado do Rio Grande do Sul, Brasil.

FIGURE 6: Curves ranch index for Hovenia dulcis of the Site I-A, located in the central area of the state of Rio Grande do Sul, Brazil. 
Assim ficou estabelecido que, para os Sítios I-B+II+III, são necessárias 6 curvas índice de sítio ( 8 a $18 \mathrm{~m}$ ), na idade índice de 25 anos (Tabela 7 e Figura 5). Já para o Sítio I-A, o número de curvas estabelecidas é a metade, iniciando na curva de $20 \mathrm{~m}$ e finalizando na de $24 \mathrm{~m}$ (Tabela 7 e Figura 6).

O número de curvas índice de sítio necessário para cobrir toda a amplitude de alturas, nos dois locais, foi definido com a plotagem dos dados levantados nas populações sobre as curvas índice elaboradas (Figura 7).

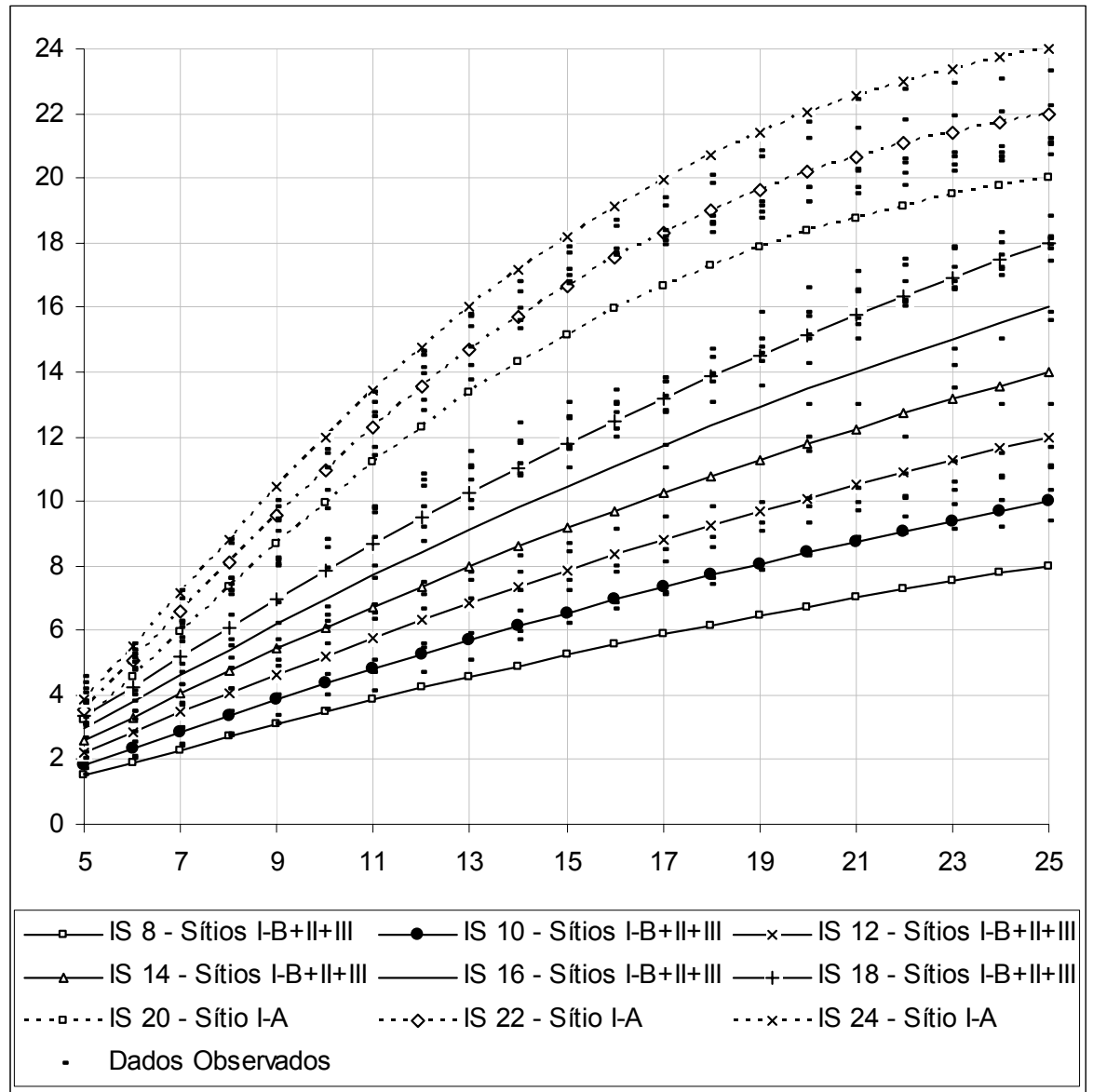

FIGURA 7: Delimitação do número de curvas índice de sítio para Hovenia dulcis dos Sítios I-A e I-B+II+III, localizados na região central do estado do Rio Grande do Sul, Brasil.

FIGURE 7: Delimitação of the number of curves ranch index for Hovenia dulcis of the Site I-A and I-B+II+III, located in the central area of the state of Rio Grande do Sul, Brazil.

\section{Confiabilidade e estabilidade das curvas de índice de sítio}

Os testes de confiabilidade e estabilidade são feitos plotando-se dados de crescimento real sobre as curvas índices de sítio, permitindo avaliar de forma gráfica o comportamento das árvores quanto a uma possível mudança de índice ao longo do tempo, assim como avaliar a estabilidade ao se classificar sítios em idades jovens.

Para a realização dos testes foram plotados dados de altura real sobre curvas índice de sítio projetado. Os resultados estão representados nas Figuras 8 e 9. 


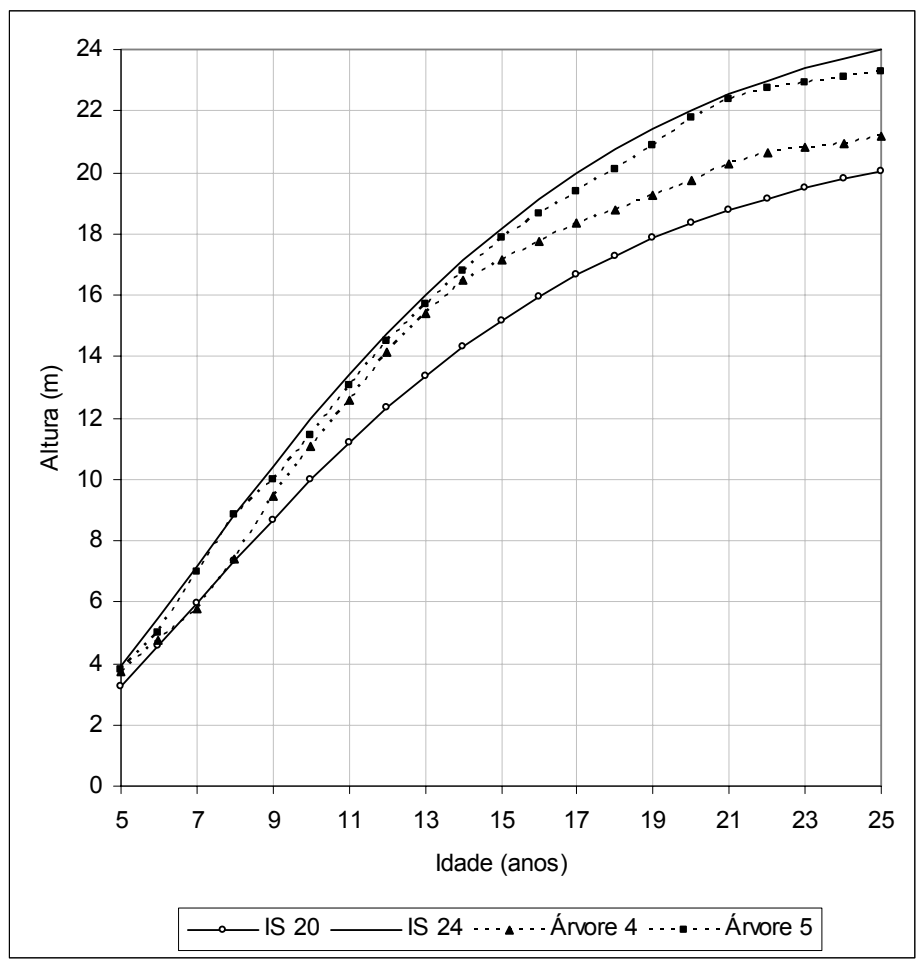

FIGURA 8: Confiabilidade e estabilidade das curvas índice para o Sítio I-A.

FIGURE 8: Reliability and stability of the curves index to the Site I-A.

Na Figura 8, verifica-se que os crescimentos reais seguem a mesma tendência das curvas índice de sítio, portanto definindo satisfatóriamente seus crescimentos.

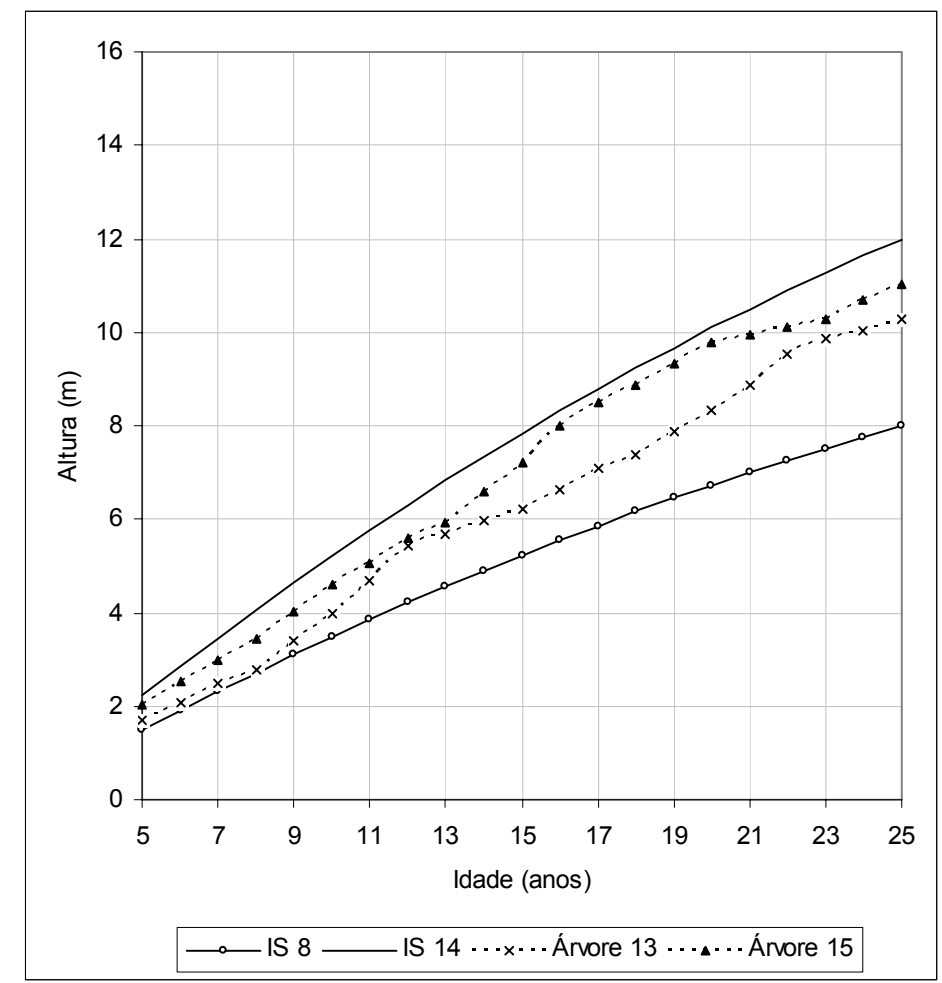

FIGURA 9: Confiabilidade e estabilidade das curvas índice para o Sítio I-B+II+III. FIGURE 9: Reliability and stability of the curves index to the Site I-B+II+III. 
Conforme a Figura 9, o Sítio I-B+II+III apresentam os crescimentos das árvores seguindo a mesma tendência das curvas índice de sítio, ao longo de todas as idades, o que demonstra que a classificação elaborada para o local é estável e confiável.

\section{CONCLUSÕES}

De acordo com os resultados obtidos no presente estudo, concluiu-se que:

A análise de covariância definiu que entre os sítios estudados foram constatadas diferenças entre dois deles (Sítio I-A e I-B+II+III), com os testes identificando que o modelo de Backman descreve melhor a relação altura dominante e idade, para Hovenia dulcis, nas idades entre 5 e 25 anos, sendo selecionado para descrever as curvas índice de sítio;

Foram necessárias três curvas índice de sítio para o local designado como Sítio I-A, e seis para o local que compreende a união dos Sítios I-B+II+III, na idade índice de 25 anos, com intervalo de 2 m entre os índices;

Para ambos os locais, a classificação de sítio elaborada deve ser empregada com cautela em idades próximas a 5 anos, podendo incorrer em erros, com a necessidade de aferição com dados reais antes da sua utilização.

\section{REFERÊNCIAS BIBLIOGRÁFICAS}

ABRÃO, P. U. R.; GIANLUPPI, D.; AZOLIN, M. A. D. Levantamento semidetalhado dos solos da Estação Experimental de Silvicultura de Santa Maria. Porto Alegre, 1988. 75 p.

ALDER, D. Forest volume estimation and yield prediction. FAO Forestry Paper, Rome, v. 2, n. 22, p. 1-194, Jan./Dec. 1980. 194 p.

ASSMANN, E. The principles of forest yield study. New York: Pergamon Press, 1970. 506 p.

BACKMAN, G. Wachstum und organisches Zeit. Leipzing: Johann Ambrosis Barth, 1943. 192 p.

BATISTA, J. L. F.; DO COUTO, H. T. Z. Escolha de modelos matemáticos para a construção de curvas de índice de sítio para florestas implantadas de Eucalyptus sp no Estado de São Paulo. Revista do IPEF, Piracicaba, n. 32, p. 33-42, abr. 1986.

BRUCE, D.; SCHUMACHER, F. X. Forest mensuration. New York: MacGraw-Hill, 1950. 483 p.

BURGER, D. Ordenamento florestal I. 2. ed. Curitiba: Setor de Ciências Agrárias, Universidade Federal do Paraná, 1976. $224 \mathrm{p}$.

CAMPOS, J. C. C.; LEITE, H. G. Mensuração florestal: perguntas e respostas. Viçosa: UFV, 2002. 407 p.

CARMEAN, W. H. Forest site quality evaluation in the United States. USDA For. Nor. Cen. For. Exp. Sta. Reprint from Advances in Agronomy, New York, v. 27, p. 209-269, 1975.

CLUTTER, J. L. et al. Timber management: a quantitative approach. New York: John Wiley \& Sons, 1983. 333 p.

CUNHA NETO, F. R. et al. Uso da diferença algébrica para a construção de curvas de índice de sítio para Eucalyptus grandis e Eucalyptus urophylla, na região de Luiz Antonio - SP. Cerne, Lavras, v. 2, n. 2, p. 119-141, jun./dez. 1996.

DACOSTA, L. P. E. Aspectos de crescimento de povoamentos jovens de Pinus taeda L. na Província de Corrientes, república Argentina. 2008, 130 f. Tese (Doutorado em Engenharia Florestal) - Universidade Federal de Santa Maria, Santa Maria.

DRESCHER, R. Crescimento e produção de Tectona grandis Linn F., em povoamentos jovens de duas regiões do estado de Mato Grosso - Brasil. 2004. 116 f. Tese (Doutorado em Engenharia Florestal) - Universidade Federal de Santa Maria, Santa Maria.

FERREIRA, C. A. Estimativa do volume de madeira aproveitável para celulose em povoamentos de Eucalyptus spp. 1976. 104 f. Dissertação (Mestrado) - Escola Superior de Agricultura Luiz de Queiróz, Piracicaba.

FINGER, C. A. G. Fundamentos de biometria florestal. Santa Maria: CEPEF/FATEC/UFSM, 1992. 269 p.

FLORIANO, E. P. et al. Ajuste e seleção de modelos tradicionais para série temporal de dados de altura das árvores. Ciência Florestal, Santa Maria, v. 16, n. 2., p. 177-199, abr./jun. 2006.

GOOGLE EARTH. Software licensidado pela Google. v. 5.0, EUA, 2008.

GREY,D. C. On the concept of site in forestry. Southern African Forestry Journal, Menlo Park, v. 113, n.1, p. 8183, Jan./Dec. 1980.

HESS, A. F. Inter-relações no crescimento de Araucaria angustifolia (Bertol.) Kuntze em diferentes locais do Rio Grande do Sul. 2006. 177 f. Tese (Doutorado em Engenharia Florestal) - Universidade Federal de Santa Maria, Santa Maria. 
HUSCH, B; MILLER, I. C; BEERS, T. W. Forest mensuration. New York: J. Wiley, 1982. 402 p.

JONES, J. R. Review and comparison of site evaluation methods. USDA For. Serv. Res. Pap. RM-51. 1969. 27 p.

LINTAB $^{\mathrm{TM}}$. Tree-ring measurement station. Rimmtech. Hardtstr. 20-22. D-69124 Heidelbert. Germany, 2000.

MALUF, J. R. T., Nova classificação climática do estado do Rio Grande do Sul. Revista Brasileira de Agrometeorologia, Santa Maria, v. 8, n. 1, p. 141-150, jan. 2000.

MICROSOFT $®$ OFICCE EXCEL. Parte do produto Microsoft Office Professional 2003. Copryght@ 1985-2003 Microsoft Corporation. 2003.

MOSER, J. W., HALL, O. F. Deriving growth and yield functions for uneven-aged forest stands. Forest Science, Bethesda, v. 15, n. 2, p. 1983-1991, Apr. 1969.

PARVIAINEN, J., NAUMANN, N. A Finlândia e suas florestas. Revista Floresta, Curitiba, v. 1/2, n. 16, p. 5-18, jan./dez. 1986.

PIENNER, L. V., TURNBULL, K. J. The Chapman-Richards generalization of von Bertalanffy's growth model for basal area growth and yield in even-aged stands. Forest Science, Bethesda, v. 19, n. 1, p. 2-21, Feb. 1973.

RICAHRD'S, F. J. A flexible growth function for empirical use. Journal Experimental Botany, Oxford, v. 10, n. 2, p. 290-301, Jun. 1959.

RIGATTO, P. A. et al. Características físicas, químicas e anatômicas da madeira de Hovenia dulcis. Colombo: EMBRAPA Florestas, 2001. 4p. (Comunicado Técnico).

SAMMI, J. C. An appeal for a better index of site. Journal of Forest, New York, v. 3, n. 63, p. 174-176, Jan./Dec. 1965.

SAS. The SAS System for Windows. Copyright (c) 1999-2001 by SAS Institute Inc., Cary, NC, USA. 1999.

SCHEEREN, L.W. et al. Crescimento de canela-lageana, Ocotea pulchella Nees et Mart. Nees, na Depressão Central do Estado do Rio Grande do Sul. Ciência Florestal, v. 13, n.1., p. 137-144. jan./mar. 2003.

SCHNEIDER, P. R., FINGER, C. A. G., MENEZES, L. F. Fundamentos de planejamento da produção para o manejo florestal de Eucalyptus grandis (Hill) Maiden e Eucalyptus saligna Smith. Santa Maria: CEPEF/FATEC, 1988. 179 p.

SCHNEIDER, P. R.; FINGER, C. A. G. Manejo sustentado de florestas inequiâneas heterogêneas. Santa Maria: Universidade Federal de Santa Maria, 2000. 195 p.

SELLE, G. L. Classificação de sítios para Pinus taeda L., através da altura dominante, para a região de Cambará do Sul, RS, Brasil. 1993. 85 f. Dissertação (Mestrado em Engenharia Florestal) - Universidade Federal de Santa Maria, Santa Maria.

SELLE, G. L. et al. Influência de diferentes tipos de cobertura na germinação e sobrevivência de mudas de uva-dojapão. Agropecuária Catarinense, Florianópolis, v. 6, n. 4, p. 20-22, nov. 1993.

SELlE, G. L.; PAULESKI, D. T.; BRAZ, E. M. Como classificar sítios florestais através da altura dominante do povoamento. Colombo: EMBRAPA Florestas, 2008. 46 p. (Série Documentos EMBRAPA).

SPURR, S. H. Forest Inventory. New York: The Ronald Press Company, 1952. 476 p.

TONINI, H. Crescimento em altura de Pinus elliottii Engelm, em três unidades de mapeamento de solo, nas regiões da Serra do Sudeste e Litoral, no estado do Rio Grande do Sul. 2000. 113 f. Dissertação (Mestrado em Engenharia Florestal) - Universidade Federal de Santa Maria, Santa Maria.

$\mathrm{TSAP}_{\mathrm{Win}}{ }^{\mathrm{TM}}$. Software for tree-ring measurement, analisys and presentation. Rimmtech. Hardtstr. 20-22. D-69124 Heidelbert. Germany, 2000. 